Research Paper

\title{
Growth kinetics, effect of carbon substrate in biosynthesis of mcl-PHA by Pseudomonas putida Bet001
}

\author{
A.M. Gumel ${ }^{1}$, M.S.M. Annuar ${ }^{1}$, T. Heidelberg ${ }^{2}$ \\ ${ }^{1}$ Institute of Biological Sciences, Faculty of Science, University of Malaya, Kuala Lumpur, Malaysia. \\ ${ }^{2}$ Department of Chemistry, Faculty of Science, University of Malaya, Kuala Lumpur, Malaysia.
}

Submitted: February 6, 2013; Approved: September 9, 2013.

\begin{abstract}
Growth associated biosynthesis of medium chain length poly-3-hydroxyalkanoates (mcl-PHA) in Pseudomonas putida Bet001 isolated from palm oil mill effluent was studied. Models with substrate inhibition terms described well the kinetics of its growth. Selected fatty acids $\left(\mathrm{C}_{8: 0}\right.$ to $\left.\mathrm{C}_{18: 1}\right)$ and ammonium were used as carbon and nitrogen sources during growth and PHA biosynthesis, resulting in PHA accumulation of about 50 to $69 \%(\mathrm{w} / \mathrm{w})$ and PHA yields ranging from $10.12 \mathrm{~g} \mathrm{~L}^{-1}$ to $15.45 \mathrm{~g} \mathrm{~L}^{-1}$, respectively. The monomer composition of the PHA ranges from $\mathrm{C} 4$ to $\mathrm{C} 14$, and was strongly influenced by the type of carbon substrate fed. Interestingly, an odd carbon chain length (C7) monomer was also detected when $\mathrm{C}_{18: 1}$ was fed. Polymer showed melting temperature $\left(T_{\mathrm{m}}\right)$ of $42.0( \pm 0.2){ }^{\circ} \mathrm{C}$, glass transition temperature $\left(T_{\mathrm{g}}\right)$ of $-1.0( \pm 0.2)^{\circ} \mathrm{C}$ and endothermic melting enthalpy of fusion $\left(\Delta \mathrm{H}_{\mathrm{f}}\right)$ of $110.3( \pm 0.1) \mathrm{J} \mathrm{g}^{-1}$. The molecular weight $\left(M_{\mathrm{w}}\right)$ range of the polymer was relatively narrow between 55 to $77 \mathrm{kDa}$.
\end{abstract}

Key words: biopolymers, kinetics, polyesters, polyhydroxyalkanoates, Pseudomonas.

\section{Introduction}

Polyhydroxyalkanoates (PHA) are bio-polymeric materials that exhibit excellent biodegradability and biocompatibility. These biodegradable polymers possess excellent physico-mechanical properties resulting in their current increase in diverse applications. In fact they are commonly utilized in various biomedical applications spanning from drug delivery devices to tissue engineering scaffoldings (Francis, 2011).

These polymers are accumulated in vivo as cellular inclusions and serve as carbon source reserves in several bacterial species (Xue et al., 2010; Hofer et al., 2011; Gumel et al., 2012b). Among the most extensively studied bacterial species capable of accumulating these biopolymers are those belonging to genus Pseudomonas reported to accumulate intracellular PHA under limited nutrient conditions and abundant carbon source such as fatty acids (Annuar et al., 2007; Gumel, et al., 2013).

For a successful process optimization, acquisition of process kinetics information describing cell growth, prod- uct accumulation and substrate consumption is normally required (Baei et al., 2011). Several kinetics models to describe the cell growth during biosynthesis of PHA in different bacterial species have been proposed (Annuar et al., 2008; Agarry et al., 2009; Baei et al., 2011). The culture conditions, nutrient limitation and the type of feeding substrates were reported to influence the structure, quantity and quality of polymer produced. For instance, Li et al. (2011), while studying the synthesis of poly-3-hydroxybutyrate-co-3-hydroxyvelarate by mutant Pseudomonas putida KTOY06 $\Delta \mathrm{C}$ reported that change in substrates or precursors in fermentation media resulted in a defined composition of copolymer. Annuar et al. (2008) reported that ammonium limitation in a medium efficiently encouraged PHA production in P. putida PGA 1. Recently, Rai et al. (2011) reported the induction of synthesis of polyhydroxyoctanoate homopolymer in Pseudomonas mendocina CH50 by feeding sodium octanoate using two-stage seed culture techniques. 
In this study, a wild-type Pseudomonas $s p$. isolated from palm oil mill effluent, and later identified as Pseudomonas putida Bet001 was used as a model organism for medium-chain-length polyhydroxyalkaoates (mcl-PHA) production. Depending on the type of fatty acid fed in this organism, feeding oleic acid (C18:1) is observed to result in mcl-PHA accumulation comprising of both evennumbered carbon atom chain length and odd-numbered carbon atom chain length monomers. Regardless of the unsaturated fatty acids used, this organism only accumulates PHA of saturated monomers. These observations were found to be highly unusual on the basic knowledge about $\beta$-oxidation of fatty acids in PHA biosynthesis. In addition, the growth kinetics of the bacterium using ammonium ion as limiting nutrient and different types of carboxylic acids as sole carbon and energy source was studied. Furthermore, the PHA product yield, productivity and characterization were also investigated.

\section{Materials and Methods}

\section{Microorganism isolation and characterization}

The wild-type Pseudomonas $s p$. was isolated from an extended aerobic pond for the treatment of palm oil mill effluent by SIME Darby Plantation Palm Oil Industry Sdn. Bhd., Nilai, Malaysia. The culture was grown on agar media containing $\left(\mathrm{g} \mathrm{L}^{-1}\right)$ : peptone $20 ; \mathrm{K}_{2} \mathrm{SO}_{4} 10 ; \mathrm{MgCl}_{2} \cdot 6 \mathrm{H}_{2} \mathrm{O}$ 1.4; irgasan 0.025; glycerol 25.2 and agar 13.6. The inoculated agar was incubated at $30^{\circ} \mathrm{C}$. Colonies were picked for further dilution streaking on the isolation agar and this process was repeated several times until observable pure colonies were obtained. Each colony was stained with Gram, Sudan Black B and Nile Red stains (Burdon, 1946; Spiekermann et al., 1999). Colonies tested positive for $\mathrm{Su}$ dan Black B and Nile Red stains were further characterized biochemically using $\mathrm{API}^{\circledR} 20 \mathrm{NE}$ (bioMerieux ${ }^{\circledR}$ USA) biochemical typing kits, followed by transmission electron microscopy (Philips CM12, United Kingdom) analysis for possible intracellular PHA granules accumulation. The colonies observed to have PHA accumulated granules were subjected to molecular 16S rRNA characterization which was carried out using GF1 DNA extraction kits (Vivantis Sdn Bhd, Malaysia) according to manufacturer's guidelines, and subsequent purification as well as concentration of PCR product using Vivantis GF-1 Gel DNA Recovery Kit. Oligonucleotide primers (Vivantis Sdn Bhd, Malaysia) having a forward sequence of 5'CGTTCAGCTCGCCTACT3' and reverse sequence of 5'TCTGATCGATGAAGACC3' were used in DNA amplification. Post PCR analysis was done by blasting of both forward and reverse sequences against sequences in GeneBank (NCBI) and ribosomal database project II (RDPII) to search for homology sequences. Based on RDP blast neighbor-joining phylogenetic analysis, it was found that there is $99 \%$ interrelationship between an isolated strain designated as Bet001 and Pseudomonas putida strains AJ785569, AN2, BCNU106, DQ060242 and DQ087528. The extracted DNA nucleotide sequence has been deposited in European Nucleotide Archive (ENA) with accession number HE573173. The new isolated strain is identified as P. putida Bet001.

\section{Shake flask fermentation}

\section{Nutrient rich medium for biomass growth}

The growth medium contained $\left(\mathrm{g} \mathrm{L}^{-1}\right)$ : 10.0 yeast extract (Bacto USA), 15.0 nutrient broth (Merck, Germany) and 5.0 ammonium sulfate (Sigma Aldrich, Germany). The stock inoculum was aseptically introduced into this medium at a concentration of $3 \%(\mathrm{v} / \mathrm{v})$ and incubated at $30^{\circ} \mathrm{C}$, $250 \mathrm{rpm}$ for $24 \mathrm{~h}$ in a shaker incubator (Daihan $\mathrm{LabTech}^{\circledR}$, Korea). Cell biomass was harvested at $4{ }^{\circ} \mathrm{C}, 9000 \mathrm{x} g$ for 10 min using low temperature centrifuge (Sorvall RC-5C Plus, Thermo Scientific Germany). The harvested biomass was then used to seed the minimal medium.

\section{Minimal medium for PHA induction}

The minimal medium for PHA production contained, except otherwise stated $\left(\mathrm{g} \mathrm{L}^{-1}\right): 3.5 \mathrm{NaNH}_{4} \mathrm{HPO}_{4} \cdot 4 \mathrm{H}_{2} \mathrm{O}$ (Sigma Aldrich, Germany); $5.7 \mathrm{~K}_{2} \mathrm{HPO}_{4}, 3.7 \mathrm{KH}_{2} \mathrm{PO}_{4}$, and $10 \mathrm{mM}$ carboxylic acid puriss i.e. $\mathrm{C}_{8: 0}, \mathrm{C}_{12: 0}, \mathrm{C}_{16: 0}$ and $\mathrm{C}_{18: 1}$ (Sigma Aldrich, Germany) at pH $7.0( \pm 0.1)$. The pure carboxylic acid was used a sole carbon and energy source during the fermentation. Sterile $1.0 \%$ (v/v) $\mathrm{Mg}_{2} \mathrm{SO}_{4} .7 \mathrm{H}_{2} \mathrm{O}$ solution and $0.1 \%(\mathrm{v} / \mathrm{v})$ trace elements (MT) solution containing $\left(\mathrm{g} \mathrm{L}^{-1}\right): \mathrm{CaCl}_{2} \cdot 2 \mathrm{H}_{2} \mathrm{O}$ 1.47, $\mathrm{CoCl}_{2} \cdot 6 \mathrm{H}_{2} \mathrm{O}$ 2.38, $\mathrm{CuCl}_{2} .2 \mathrm{H}_{2} \mathrm{O}$ 0.17, $\mathrm{FeSO}_{4} .7 \mathrm{H}_{2} \mathrm{O} 2.78, \mathrm{MnCl}_{2} .4 \mathrm{H}_{2} \mathrm{O} 1.98$ and $\mathrm{ZnSO}_{4} .7 \mathrm{H}_{2} \mathrm{O} 0.29$ dissolved in $1 \mathrm{M} \mathrm{HCl}$ were aseptically and separately added prior to inoculum seeding. 3\% ( $\mathrm{v} / \mathrm{v})$ of harvested biomass suspended in phosphate buffer was seeded into this medium aseptically and then incubated at $30^{\circ} \mathrm{C}, 250 \mathrm{rpm}$ for a total period of $48 \mathrm{~h}$ except otherwise stated.

\section{PHA extraction}

The accumulated PHA was extracted according to previously reported literature (Gumel et al., 2012a). PHA accumulated biomass was harvested by centrifugation at 9000 x $g$ (Sorvall RC-5C Plus, Thermo Scientific Germany) for $10 \mathrm{~min}$. The supernatant was discarded while $10 \%(\mathrm{v} / \mathrm{v}) n$-hexane in distilled water was used to wash the pellets three times to remove residual fatty acids. Later, the biomass was dried in vacuo in the presence of phosphorus pentaoxide using vacuum drying oven VC-6020 (Constance, Germany) at $45^{\circ} \mathrm{C}$ for $24 \mathrm{~h}$. About $10 \%$ (w/v) dried biomass was suspended in chloroform and refluxed at $80{ }^{\circ} \mathrm{C}$ for $4 \mathrm{~h}$, after which Buchner flask equipped with $0.2 \mu \mathrm{m}$ PTFE filter paper was used to filter the reflux mixture under vacuum. The filtrate was concentrated in rotary evaporator (Yamato RE300; Yamato, Japan) at $4{ }^{\circ} \mathrm{C}$ under reduced pressure until about $5 \%$ of the original volume. 
The polymer was then precipitated in cold methanol while being gently stirred. The PHA solution was allowed to settle under gravity for $24 \mathrm{~h}$ after which the supernatant was decanted leaving behind a layer of PHA film. This film was air-dried before the purification steps were repeated by chloroform dissolution and methanol extraction. The PHA film was dried in vacuo prior to characterization and quantification.

\section{Analyses}

\section{Biomass estimation}

A standard calibration of known biomass dry weight concentrations in $0.05 \mathrm{M}$ phosphate buffer and absorbance at $600 \mathrm{~nm}$ was constructed using Jasco V-630 UV/VIS spectrophotometer (Jasco, Japan). Samples aliquotes were withdrawn aseptically at regular intervals and centrifuge at $9000 \mathrm{x} g$ for $10 \mathrm{~min}$, and then washed with $0.05 \mathrm{M}$ phosphate buffer twice and finally suspended in the same buffer prior to absorbance reading against the phosphate buffer blank.

\section{Ammonium (limiting substrate) quantification}

Ammonium sodium hydrogen phosphate tetrahydrate $\left(\mathrm{NaNH}_{4} \mathrm{HPO}_{4} \cdot 4 \mathrm{H}_{2} \mathrm{O}\right.$; Sigma Aldrich-Germany) was used as the source of nitrogen that serves as the limiting nutrient. Residual ammonium was quantified using phenol hypoclorite method as described by Solorzano (1969). About $2 \mathrm{~mL}$ of cell free suspension was diluted with distilled water to $5 \mathrm{~mL}$. To this solution $0.2 \mathrm{~mL}$ of alcoholic phenol (10 g phenol in $90 \mathrm{~mL}$ absolute ethanol) was added followed by the addition of $0.2 \mathrm{~mL}$ of $0.5 \%(\mathrm{w} / \mathrm{v})$ sodium nitroperusside aqueous solution. A $0.5 \mathrm{~mL}$ oxidizing solution containing 4:1 $(v / v)$ alkaline solution (100 g trisodium citrate, $5 \mathrm{~g}$ sodium hydroxide dissolved in $500 \mathrm{~mL}$ distilled water) and sodium hypochlorite solution $(1.5 \mathrm{~N})$ was added to the mixture. Each sample was mixed vigorously using vortex mixer after each reagent addition to ensure uniform color formation. The mixture was then allowed to stand for an hour at room temperature $\left(25^{\circ} \mathrm{C}\right)$ resulting in light-blue coloration that was read at $640 \mathrm{~nm}$ against distilled water as blank. Residual ammonium concentration was then quantified based on a standard calibration of known ammonium concentrations.

\section{Residual fatty acid quantification}

The quantification of residual fatty acid was performed according to Marseno et al. (1998) modified protocol. $1.0 \mathrm{~mL}$ cell free suspension was mixed with $n$-heptane $(3 \mathrm{~mL})$ and centrifuged at $9000 \times \mathrm{g}$ to separate the residual fatty acid. About $2 \mathrm{~mL}$ of the top layer of $n$-heptane was withdrawn into a test tube, and to this solution $200 \mu \mathrm{L}$ of $5 \%(\mathrm{w} / \mathrm{v})$ copper II acetate monohydrate solution (5 g copper II acetate monohydrate dissolved in $90 \mathrm{~mL}$ distilled water; pyridine and distilled water were used to adjust the solution $\mathrm{pH}$ to 6 and bring the final volume to $100 \mathrm{~mL}$ ) was added followed by vortex-mixing for $60 \mathrm{~s}$ before allowed to stand for $20 \mathrm{~s}$. The sample was then read at $705 \mathrm{~nm}$ using Jasco V-630 UV/VIS spectrophotometer (Jasco, Japan) against distilled water as blank. A standard calibration was constructed based on different fatty acid concentrations (2 to $10 \mathrm{mM}$ ) that were made by dissolving the specified mass of a particular fatty acid in $n$-heptane and treated as mentioned earlier.

\section{PHA authentication}

\section{FTIR spectroscopy}

Perkin-Elmer FTIR spectrum-400 spectrometer (Perkin-Elmer Inc., Wellesley, MA, USA) was used to record the infra-red spectrum at room temperature over a range of 400 to $4000 \mathrm{~cm}^{-1}$ for 10 scans. About $0.01 \mathrm{~g}$ of the sample was dissolved in chloroform, which was then applied on to $\mathrm{KBr}$ crystal window to form a thin film. The spectrum was read after evaporation of the solvent under vacuum.

\section{Proton NMR analysis}

The ${ }^{1} \mathrm{H}$ NMR spectrum was recorded on a JEOL JNM-GSX 270 FT-NMR (JOEL Ltd, Tokyo, Japan) at $250 \mathrm{MHz}$ against tetramethylsilane (TMS) as internal reference standard. About $5 \mathrm{mg}$ PHA sample was dissolved in $2 \mathrm{~mL}$ deutrated chloroform $\left(\mathrm{CDCl}_{3}\right)$ and filtered into NMR tube using borosilicate glass syringe equipped with $0.22 \mu \mathrm{m}$ PTFE disposable filter (11807-25, Sartorius Stedim, Germany).

\section{GC-MS and GC-MSMS analyses}

The gas chromatography-mass spectrometry (GCMS) analysis was performed on Shimadzu GCMS-QP2010 plus (Shimadzu, Japan), equipped with GC-MS triple axes detector carrying Agilent DB-5 column (30 m length $\mathrm{x}$ $0.25 \mathrm{~mm}$ internal diameter $\mathrm{x} 0.25 \mu \mathrm{m}$ film). PHA sample in the form of hydroxyalkanoic methyl esters were used for the GC-MS analysis. PHA samples were hydrolyzed according to the methods reported in literature (Grothe and Chisti, 2000). About $10 \mathrm{mg}$ of purified PHA was dissolved in $1 \mathrm{~mL}$ chloroform in a screw-capped tube; to this mixture $1.0 \mathrm{~mL}$ of acidified methanol containing $2.8 \mathrm{M} \mathrm{H}_{2} \mathrm{SO}_{4}$ was added. The tube was tightly capped and sealed with PTFE tape, then heated at $110{ }^{\circ} \mathrm{C}$ using WiseTherm ${ }^{\circledR} \mathrm{HB} 48$ digital heating block (Daihan Scientific, Korea) for $2 \mathrm{~h}$ after which it was cooled down to room temperature. Phase separation of the hydrolyzed mixture was induced by the addition of $1 \mathrm{~mL}$ demineralized water followed by vortex-mixing for $30 \mathrm{~s}$. The mixture was then allowed to stand for 5 min after which the methyl esters were carefully recovered from the organic phase at the bottom of the tube using glass Pasteur pipette into a $2 \mathrm{~mL}$ sample vial. $1 \mu \mathrm{L}$ sample was automatically injected at $280^{\circ} \mathrm{C}$ and $50: 1$ split ratio into the GC-MS. The oven and column temperatures were programmed at $40{ }^{\circ} \mathrm{C}$ for $1 \mathrm{~min}$, then increased to 
$120^{\circ} \mathrm{C}$ at a rate of $15^{\circ} \mathrm{C} \mathrm{min}^{-1}$, then kept constant for $2 \mathrm{~min}$. Subsequently, the temperature was increased to $250{ }^{\circ} \mathrm{C}$ at $10^{\circ} \mathrm{C} \mathrm{min}^{-1}$ and then held constant for $20 \mathrm{~min}$. Helium was used as carrier gas at $48.3 \mathrm{~mL} \mathrm{~min}^{-1}$ and 0.41 bar head pressure. Mass spectra were acquired at 1250 scan speed using electron impact energy of $70 \mathrm{eV}$ at $200{ }^{\circ} \mathrm{C}$ and $280{ }^{\circ} \mathrm{C}$ ion-source and interface temperatures, respectively. Standard monomers of methyl hydroxyalkanoates (Larodan, Sweden) and NIST08 MS spectra library were used as reference for peak retention time and ionization mass determination, respectively.

In addition to GC-MS analysis, to further confirm the results obtained, GC-MSMS spectrum was also recorded on Agilent triple quadrupole 7000B (Agilent, USA), equipped with GC-MSMS triple axis detector carrying Agilent HP-5ms column (30 m length x $0.25 \mathrm{~mm}$ internal diameter x $0.25 \mu \mathrm{m}$ film).

\section{Gel permeation chromatography (GPC)}

Gel permeation chromatography was carried out using Waters 600 (Waters Corp, Milford, MA, USA) GPC system equipped with Waters refractive index detector (model 2414) having the following gel columns $(7.8 \mathrm{~mm}$ internal diameter; $300 \mathrm{~mm}$ ) in series: HR1, HR2, HR5E and HR5E Waters Styrogel HR-THF. Monodisperse polystyrene standards of different molecular weights $\left(3.72 \times 10^{2}\right.$, $2.63 \times 10^{3}, 9.10 \times 10^{3}, 3.79 \times 10^{4}, 3.55 \times 10^{5}, 7.06 \times 10^{5}$, $3.84 \times 10^{6}$ and $6.77 \times 10^{6} \mathrm{Da}$ ) were used for the calibration curve. The PHA samples were dissolved in tetrahydrofuran (THF) at a concentration of $2.0 \mathrm{mg} \mathrm{mL}^{-1}$, and then filtered through a $0.22 \mu \mathrm{m}$ PTFE filter. $100 \mu \mathrm{L}$ aliquot sample was injected at $40^{\circ} \mathrm{C}$. THF was used as a mobile phase at a flow rate of $1.0 \mathrm{~mL} \mathrm{~min}^{-1}$.

\section{Differential scanning calorimetry (DSC)}

Mettler Toledo differential scanning calorimeter (DSC 822e; Mettler Toledo, USA) equipped with HAAKE EK90/MT digital immersion cooler (Thermo Fischer Scientific, USA) was used for the DSC analysis of the synthesized polymer. Scans were made at a temperature range of $-60{ }^{\circ} \mathrm{C}$ to $180{ }^{\circ} \mathrm{C}$ at a heating rate of $10^{\circ} \mathrm{C} \mathrm{min}^{-1}$ under nitrogen flow rate of $0.12 \mathrm{~L} \mathrm{~min}^{-1}$ and a head pressure of 1.5 bar. The melting temperature $\left(T_{\mathrm{m}}\right)$ was taken at the endothermic peak of the DSC thermogram. The DSC endothermic melting enthalpy $\left(\Delta H_{\mathrm{m}}\right)$ was used to calculate the polymer crystallinity $\left(X_{\mathrm{p}}\right)$ on the basis of melting enthalpy $\left(\Delta H_{\mathrm{m}}{ }^{\mathrm{o}}\right)$ of $100 \%$ crystalline poly-3-hydroxybutyrate (PHB) according to Eq. (1) as reported elsewhere (Dai et al., 2008), assuming $142 \mathrm{~J} \mathrm{~g}^{-1}$ as the melting enthalpy of $100 \%$ crystalline PHB as cited in literature (Liu et al., 2009).

$$
X_{p}=\frac{\Delta H_{m}}{\Delta H_{m}^{0}}
$$

\section{Thermogravimetric analysis (TGA)}

TGA analysis was performed on a Perkin-Elmer TGA 4000 instrument as reported previously (Gumel et al., 2013). In brief, the sample was heated from $50^{\circ} \mathrm{C}$ to $900{ }^{\circ} \mathrm{C}$ at a rate of $10^{\circ} \mathrm{C} \mathrm{min}^{-1}$ under a nitrogen flow rate of $20 \mathrm{~mL}$ $\min ^{-1}$.

\section{Numerical calculations}

In batch microbial fermentation under balance growth, the rate of limiting substrate consumption with time is assumed to follow first order kinetics as given by Eq. (2)

$$
\frac{d S}{d t}=-r_{s} \cdot S
$$

re-arranging and integrating Eq. (2) gives Eqs. (3) and (4), respectively,

$$
\int_{S_{0}}^{S} \frac{1}{S} \cdot d S=-r_{s} \cdot \int_{o}^{t} d t
$$

hence

$$
\ln S_{0}-\ln S=r_{s} \cdot t
$$

where $S$ is limiting substrate concentration $\left(\mathrm{g} \mathrm{L}^{-1}\right), S_{\mathrm{o}}$ is the initial value for $S$ and $r_{\mathrm{s}}$ is the substrate consumption rate $\left(\mathrm{h}^{-1}\right)$.

The specific growth rate $\left(\mu \mathrm{h}^{-1}\right)$ with respect to the rate of change of biomass concentration is given by Eq. (5)

$$
r_{x}=\frac{d C_{x}}{d t}=\mu \cdot C_{x}
$$

where $C_{x}$ is the actual catalytic biomass calculated as the difference between total biomass concentration $\left(C_{x}^{\prime}\right)$ and PHA concentration ([P]).

However, with respect to substrate consumption, the specific growth rate was compared based on Monod and Tessier kinetics models (Eqs. (6) and (7)) without substrate inhibition. Comparing the kinetics under substrate inhibition, the specific growth rate was modeled by Andrews, Aiba, Tessier-type and Webb kinetics models (Eqs. (8)(11) respectively).

$$
\begin{aligned}
& \mu=\frac{\mu_{\max } \cdot S}{K_{S}+S} \\
& \mu=\mu_{\max } \cdot\left(1-\exp ^{\left.\left(\frac{-S}{K_{i}}\right)\right)}\right)
\end{aligned}
$$




$$
\begin{aligned}
& \mu=\frac{\mu_{\text {max }}}{\left(1+\frac{K_{S}}{S}\right)\left(1+\frac{S}{K_{i}}\right)} \\
& \mu=\mu_{\text {max }} \cdot\left(\frac{S}{K+S}\right) \cdot \exp ^{\left(\frac{-S}{K_{i}}\right)} \\
& \mu=\mu_{\text {max }} \cdot\left(\exp \left(\frac{-S}{K_{i}}\right)-\exp ^{\left(\frac{-S}{K_{s}}\right)}\right) \\
& \mu=\mu_{\text {max }} \cdot \frac{S \cdot\left(1+\frac{S}{K_{i}}\right)}{K_{s}+S+\left(\frac{S^{2}}{K_{i}}\right)}
\end{aligned}
$$

where $\mu_{\max }$ is the maximum specific growth rate, $K_{\mathrm{s}}$ denotes the Monod constant $\left(\mathrm{g} \mathrm{L}^{-1}\right)$ and $K_{\mathrm{i}}$ substrate inhibition constant.

The cell biomass $(C)$ yield with respect to the limiting nitrogen substrate $(S)\left(\mathrm{g} \mathrm{g}^{-1}\right)$ is given by Eq. (12)

$$
Y_{C_{x} / S}=\frac{d[C]}{d S}
$$

where $C$ and $S$ are cell biomass and substrate concentrations $\left(\mathrm{g} \mathrm{L}^{-1}\right)$, respectively.
The PHA $[P]$ yield with respect to the carbon substrate $\left(S_{x}\right)\left(\mathrm{g} \mathrm{g}^{-1}\right)$ is given by Eq. (13)

$$
Y_{[P] / S_{x}}=\frac{d[p]}{d S_{x}}
$$

where $[P]$ and $S_{x}$ are PHA and carbon substrate concentrations $\left(\mathrm{g} \mathrm{L}^{-1}\right)$, respectively.

The volumetric productivity, $\Phi\left(\mathrm{g} \mathrm{L}^{-1} \mathrm{~h}^{-1}\right)$ was calculated according to literature (Annuar, et. al. 2006) as in Eq. (14)

$$
\Phi=\frac{[P]}{t_{f}}
$$

where $[P]$ is the PHA concentration $\left(\mathrm{g} \mathrm{L}^{-1}\right)$ at fermentation time $t_{\mathrm{f}}(\mathrm{h})$.

\section{Results and Discussions}

\section{Strain characterization and PHA production}

Sudan Black B staining was used in the microscopic observation for a possible accumulation of intracellular PHA by the isolated strain. Further confirmation of the presence of accumulated granule was made by transmission electron microscopy (Figure 1a). The bacterial strain was further characterized using biochemical analyses and $16 \mathrm{~S}$ rRNA molecular characterization. The biochemical analy-

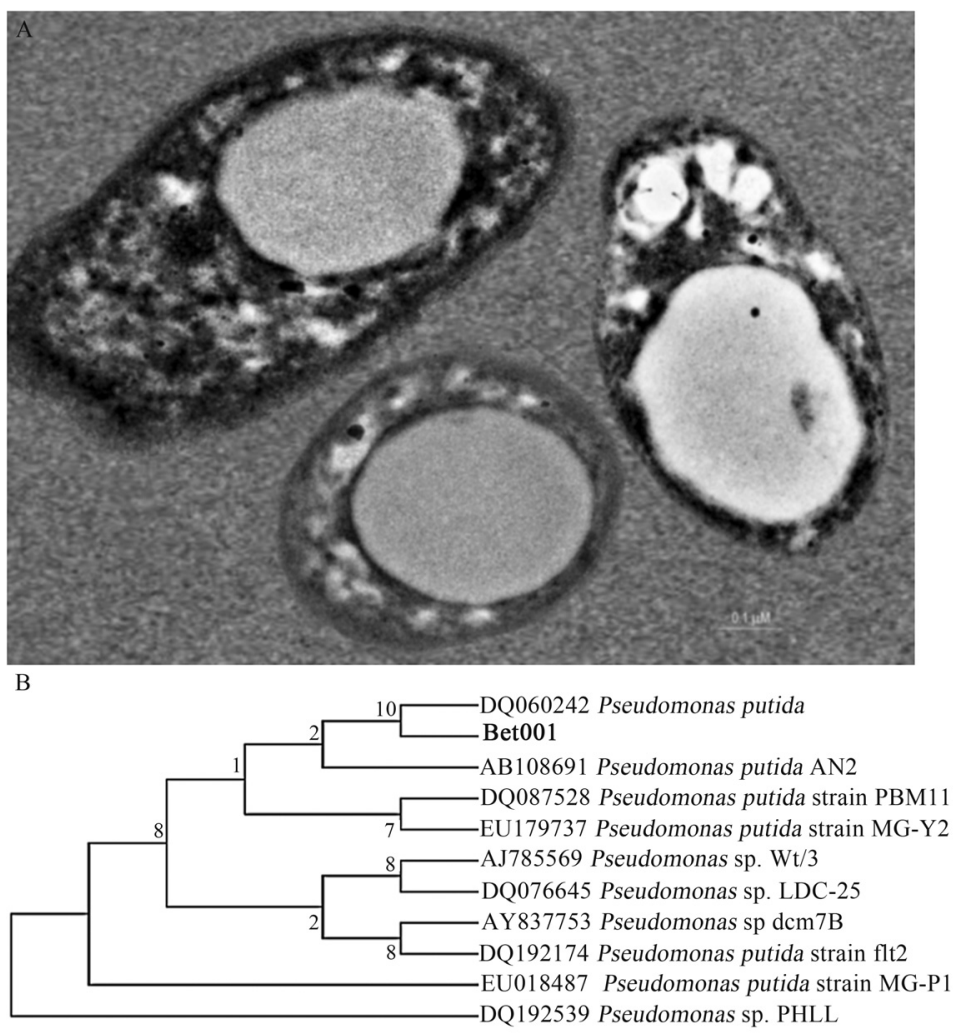

Figure 1 - (a) T.E.M micrograph of Pseudomonas putida Bet001 containing PHA inclusion (x8000). (b) Neighbor joining phylogenetic tree showing the interrelationship between isolate Bet001 and top 10 Blast hits from RDP II database 
ses indicated a probability of $99.5 \%$ for the isolate to be identified as Pseudomonas putida. The ribosomal database project II (RDPII) homology search and blasting of the obtained results from 16S rRNA molecular characterization of the isolate Bet001 showed $99 \%$ analogy between this isolate and Pseudomonas putida strains AJ785569, AN2, BCNU106, DQ060242 and DQ087528 (Figure 1b). Henceforth, the isolate was designated as P. putida Bet001 and subsequently used in the PHA production in batch fermentation process using selected fatty acids $\left(\mathrm{C}_{8: 0}\right.$ to $\left.\mathrm{C}_{18: 1}\right)$ as a carbon source. Depending on the carbon source used, the PHA accumulation was observed to span from 50 to $69 \%$ (w/w) after $48 \mathrm{~h}$. This observed PHA accumulation was found to be within the range of previously reported literatures in P. putida (Lee et al., 2000) and P. oleovorans (Kim, 2002).

\section{Authentication of extracted PHA}

\section{FTIR spectroscopy}

The FTIR spectra of the extracted PHA showed amorphous PHA characteristics (Figure 2). The observed $3420.20 \mathrm{~cm}^{-1}$ absorption band is indicative of the presence of hydroxyl group in a polymer chain (Ma et al., 2009). Absorption band $2955.76 \mathrm{~cm}^{-1}$ is assigned to asymmetric methyl group. The stretching vibration $2925.98 \mathrm{~cm}^{-1}$ is allocated to asymmetric $\mathrm{CH}_{2}$ of the lateral monomeric chains. The absorption at $2855.99 \mathrm{~cm}^{-1}$ is assigned to symmetrical $\mathrm{CH}_{3}$ and the intensity of the band has been reported to be due to conformational disorder obtained in the process of crystallization (Liu et al., 2011), suggesting that the polymer is less crystalline. Absorption band $1741.44 \mathrm{~cm}^{-1}$ has been reported to be a PHA marker band assigned to carbonyl ester $(\mathrm{RC}=\mathrm{O})$ stretching vibration. The vibration at $1469.77 \mathrm{~cm}^{-1}$ have been assigned to bacterial protein amide II ( $\mathrm{NC}=\mathrm{O})$ in the cell (Randriamahefa et al., 2003). Absorption at $1378.83 \mathrm{~cm}^{-1}$ is assigned to terminal $\mathrm{CH}_{3}$ groups (Vishnuvardhan et al., 2009). Absorption at $1259.89 \mathrm{~cm}^{-1}$ is due to asymmetric C-O-C stretching vibration. Series of absorption bands at $1166.87 \mathrm{~cm}^{-1}$ to $619.39 \mathrm{~cm}^{-1}$ were assigned to $\mathrm{C}-\mathrm{O}$ and $\mathrm{C}-\mathrm{C}$ stretching vibration in the amorphous phase. The crystallinity index of this polymer was observed to be 1.1 from the band area ratio of crystalline $\mathrm{C}-\mathrm{O}-\mathrm{C}$ stretching vibration at $1259.89 \mathrm{~cm}^{-1}$ due to polymer crystallization to that of the amide band at $1469.77 \mathrm{~cm}^{-1}$ as reported in literature (Xu et al., 2002; Kansiz et al., 2007).

\section{${ }^{1} H$ NMR characterization of extracted PHA}

${ }^{1} \mathrm{H}$ NMR spectrum of the extracted PHA dissolved in $\mathrm{CDCl}_{3}$ is shown in Figure 3. With reference to internal standard trimethylsilane, the observed multiplet peaks number $1(\delta 2.66-2.44 \mathrm{ppm})$ and triplet peaks $2(\delta 5.25-5.14 \mathrm{ppm})$ are assigned to methylene and methine protons of the $\alpha$ and $\beta$-carbon, respectively (Huijberts et al., 1992; Haba et al., 2007; Chung et al., 2011). Peak number 3 ( $1.58 \mathrm{ppm}$ ) is assigned to methylene protons in the side-chains (Huijberts et al., 1992; Haba et al., 2007; Chung et al., 2011). Multiplet peaks $4(\delta 1.33-1.25)$ and triplet number $5(\delta 0.94-0.85)$ are assigned to the methylene protons and terminal methyl proton of the side-chains respectively (Huijberts et al., 1992; Haba et al., 2007; Chung et al., 2011). Although the observed peaks $(x, y, z)$ were previously assigned to the presence of unsaturation in the side-chain of PHA based on

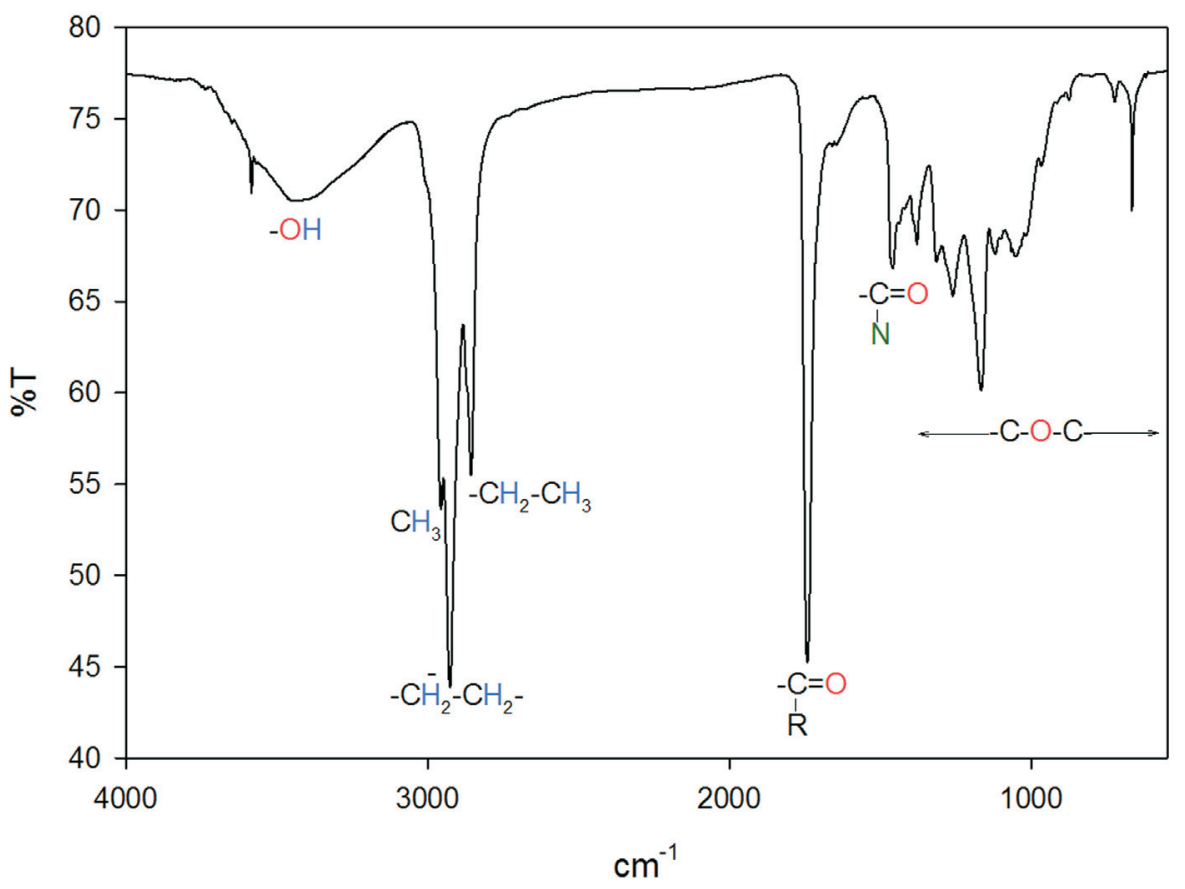

Figure 2 - Nondestructive FTIR-ATR spectrum of the extracted PHA from P. putida Bet001 using oleic acid $\left(\mathrm{C}_{18: 1}\right)$ as carbon source. 


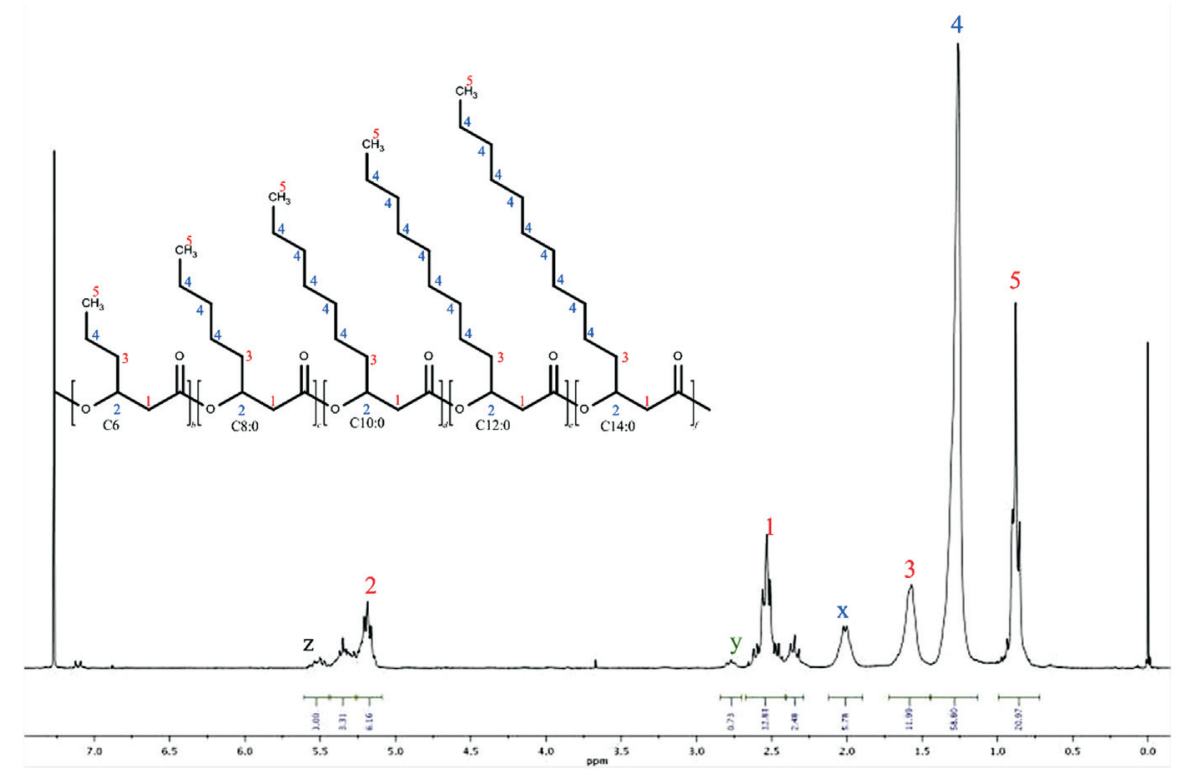

Figure 3 - ${ }^{1}$ H NMR spectrum of the PHA produced by P. putida Bet001 using oleic acid $\left(\mathrm{C}_{18: 1}\right)$ as carbon source.

NMR and GC analyses (Huijberts et al., 1992; Grothe and Chisti, 2000; Haba et al., 2007; Sin et al., 2010), further analysis based on GC-MS (data not shown) indicated the absence of the corresponding double bond of 3-hydroxyalkanoate (3HA) methyl esters or their trans-2-alkenoic acids. The GC-MS data only showed the presence of saturated 3HA methyl esters, their corresponding trans-2-alkenoic acids and fatty acids methyl ester of oleate $\left(\mathrm{C}_{18: 1}\right)$ and palmitate $\left(\mathrm{C}_{16: 0}\right)$. These fatty acids were known to be among the major component of phospholipids in the cellular membrane. We therefore concluded that the peaks $(x, y$, $z$ ) normally assigned to the unsaturated side-chain in the PHA is simply due to hydrophobic oleate and palmitate from the cellular membrane lipids inadvertently extracted along during the solvent reflux extraction.

\section{Thermal analyses}

Depending on the carbon source used, in the DSC thermogram (data not shown), the endothermic melting temperature $\left(T_{\mathrm{m}}\right)$ of this polymer was observed to range from 43.3 to $66.5( \pm 0.2)^{\circ} \mathrm{C}$ and glass transition temperature $\left(T_{\mathrm{g}}\right)$ of -1.0 to $1.0( \pm 0.2){ }^{\circ} \mathrm{C}$. The observed characteristic low melting and glass transition temperatures were attributed to the random composition of 3-hydroxyalkanoates as reported previously (Matsusaki et al., 2000). An apparent enthalpy of fusion $\left(\Delta H_{\mathrm{f}}\right)$ of $110.3( \pm 0.1) \mathrm{J} \mathrm{g}^{-1}$ has been observed. The relatively low enthalpy of fusion as compared to $145.3 \mathrm{~J} \mathrm{~g}^{-1}$ for PHB could be due to the amorphous nature of the polymer (Mark, 1999). In the gravimetric thermogram (Figure 4), there is an observed relationship between the fatty acid chain length fed and the polymer thermal stability. For instance, feeding lauric acid resulted in PHA polymer with TGA degradation temperature $\left(T_{\mathrm{d}}\right)$ of $264.6^{\circ} \mathrm{C}( \pm 0.2)$, changing the fatty acid to palmitic acid or oleic acid resulted in polymer production with degradation temperature at $302.2{ }^{\circ} \mathrm{C}( \pm 0.2)$ and $318.8^{\circ} \mathrm{C}( \pm 0.2)$, respectively. This increase in thermal stability with increased fatty acid chain length is suggested to be due to the increase in the longer chain monomer fraction, which has been reported to favor side-chain crystallization resulting in polymer with relatively high degradation temperature. This observation was also found to be in agreement with reported literature (Siracusa et al., 2008; Ma et al., 2009; Liu et al., 2011). Previously, Ma et al. (2009) observed an increase in both $T_{m}$ and $\Delta H_{m}$ with increasing content of the long side-chain co-monomer unit during mcl-PHA biosynthesis in P. putida KT2442. They proposed a possible side-chain crystallization effect by the longer side-chain co-monomers, leading to a higher melting temperature. Their observation was further corroborated recently by Liu et al. (2011), while observing mcl-PHA biosynthesis in mutant $P$. putida KT2442 reporting an increase in thermal parameters of the accumulated polymer with increasing long-chain monomer and attributing this observation to side chain crystallization leading to an improved mcl-PHA mechanical properties.

\section{Growth kinetics parameters as a function of limiting substrate}

Based on the kinetics models listed in numerical calculation section (Eqs. (6) through (11)), the experimental data was observed to fit models with substrate inhibition term better than those without the substrate inhibition term (Figure 5), having a maximum specific growth rate $\left(\mu_{\max }\right)$ of $0.21( \pm 0.01) \mathrm{h}^{-1}$ and a $K_{\mathrm{s}}$ value of $0.82 \times 10^{-2}( \pm 0.01) \mathrm{M}$ (Table 1). In Figure 6, it was observed that $\mu$ increased with 


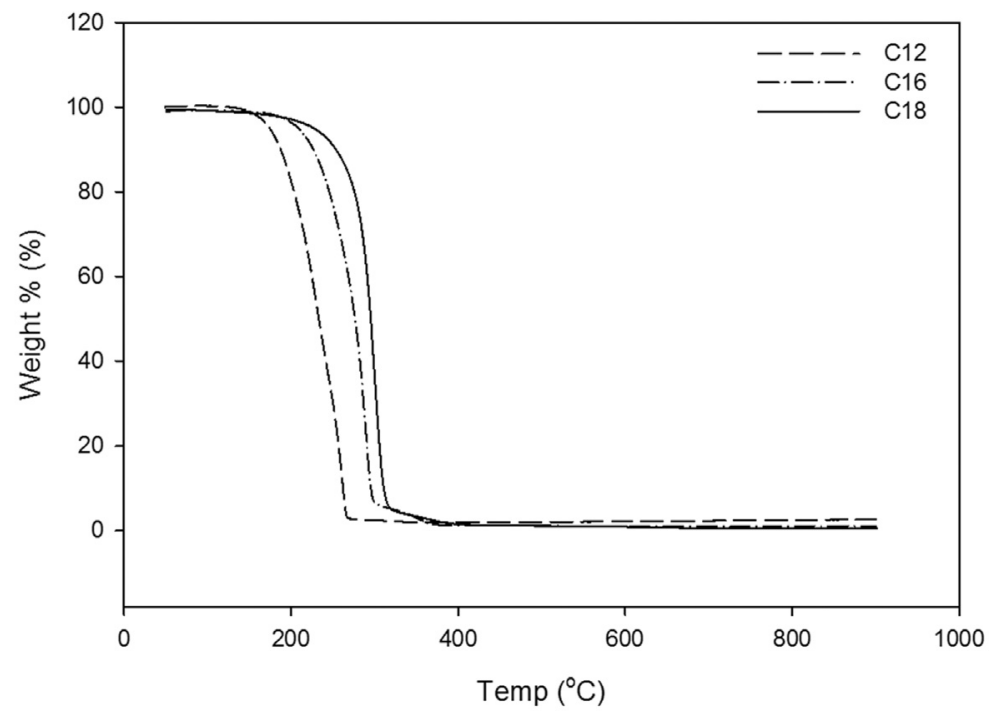

Figure 4 - TGA thermogram of the PHA produced by P. putida Bet001 using different type of fatty acids as sole carbon and energy source.

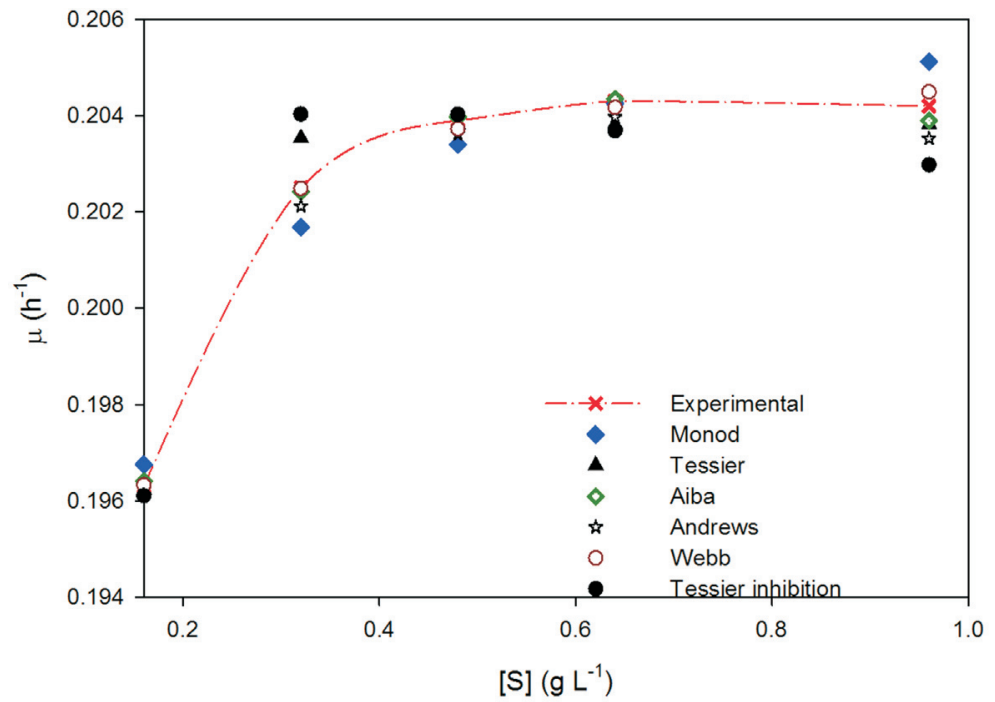

Figure 5 - Fitting of growth data of $P$. putida Bet001 with different growth models. The bacterium was grown in oleic acid $\left(\mathrm{C}_{18: 1}\right)$ as a sole carbon and energy source.

increasing nitrogen source to a maximum value at $0.1 \mathrm{~g} \mathrm{~L}^{-1}$ ammonium ion, with a polymer yield of $57 \%(\mathrm{w} / \mathrm{w})$ cell dry weight (CDW). Increasing ammonium ion concentration beyond this point did not improve the specific growth rate and the polymer yield (Figure 6). Annuar et al. (2006) reported a decrease in specific growth rate and low PHA accumulation at higher concentrations of ammonium ion > $0.1 \mathrm{~g} \mathrm{~L}^{-1}$. This observation could probably be due to the high level NADPH generated in presence of high nitrogen sources, which is known to be the coenzyme of ATP and acetoacetyl-CoA reductase in the PHA biosynthetic pathway. In fact, $\mathrm{CoA}$ is known to inhibit both pha $A$ and pha $C$, while pha $B$ is inhibited by NADP ${ }^{+}$. Therefore polymer bio- synthesis is highly reduced if any of these are present in large amounts (Satoh et al., 2003; Thomson et al., 2010).

The observation in this study was found to be in good agreement with reported results (Albuquerque et al., 2010; Francis, 2011; Ng et al., 2011). Venkateswar Reddy and Venkata Mohan (2012) observed an increased in PHA accumulation from 38 to $45 \%$ by reducing nitrogen source concentration from $300 \mathrm{mg} \mathrm{L}^{-1}$ to $100 \mathrm{mg} \mathrm{L}^{-1}$ during PHA biosynthesis using mixed microbial consortia in waste water treatment. 
Table 1 - Comparison of kinetics parameters.

\begin{tabular}{|c|c|c|c|c|c|c|}
\hline Model & $\mu_{\max }\left(\mathrm{h}^{-1}\right)$ & $K_{S}\left(\mathrm{~g} \mathrm{~L}^{-1}\right)$ & $K_{i}\left(\mathrm{~g} \mathrm{~L}^{-1}\right)$ & Correlation coefficient $\left(\mathrm{R}^{2}\right)$ & Variance $(\sigma)$ & Ref \\
\hline \multicolumn{7}{|c|}{ Kinetics models without substrate inhibition } \\
\hline \multirow[t]{3}{*}{ Monod } & 0.21 & $0.82 \times 10^{-2}$ & & 0.96 & $6.57 \times 10^{-7}$ & This research \\
\hline & 0.17 & $0.83 \times 10^{-2}$ & & 0.91 & $4.29 \times 10^{-4}$ & (5) \\
\hline & 0.17 & $0.86 \times 10^{2}$ & & 0.98 & - & (6) \\
\hline \multirow[t]{2}{*}{ Tessier } & 0.20 & $0.49 \times 10^{-1}$ & & 0.97 & $4.88 \times 10^{-7}$ & This research \\
\hline & 0.16 & 0.01 & & 0.96 & $2.04 \times 10^{-4}$ & $(5)$ \\
\hline \multicolumn{7}{|c|}{ Kinetics models with substrate inhibition } \\
\hline \multirow[t]{2}{*}{ Andrews } & 0.21 & $0.11 \times 10^{-1}$ & $0.39 \times 10^{-1}$ & 0.98 & $4.00 \times 10^{-7}$ & This research \\
\hline & 0.23 & $0.19 \times 10^{-1}$ & $0.19 \times 10^{-1}$ & 0.99 & $5.60 \times 10^{-5}$ & (5) \\
\hline \multirow[t]{3}{*}{ Aiba } & 0.21 & $0.11 \times 10^{-1}$ & $0.12 \times 10^{-1}$ & 0.99 & $5.90 \times 10^{-8}$ & This research \\
\hline & 0.22 & $0.17 \times 10^{-1}$ & 1.69 & 0.99 & $7.55 \times 10^{-5}$ & (5) \\
\hline & 0.23 & $3.76 \times 10^{-4}$ & 2.01 & - & - & (1) \\
\hline \multirow[t]{2}{*}{ Tessier Inhibition } & 0.21 & $0.51 \times 10^{-1}$ & 0.91 & 0.91 & $2.14 \times 10^{-6}$ & This research \\
\hline & 0.19 & $0.27 \times 10^{-1}$ & 2.68 & 0.99 & $2.54 \times 10^{-5}$ & $(5)$ \\
\hline \multirow[t]{2}{*}{ Webb } & 0.20 & $0.16 \times 10^{-1}$ & $0.16 \times 10^{-1}$ & 0.99 & $6.75 \times 10^{-8}$ & This research \\
\hline & 0.22 & $9.15 \times 10^{-1}$ & $3.60 \times 10^{-3}$ & - & - & (1) \\
\hline
\end{tabular}

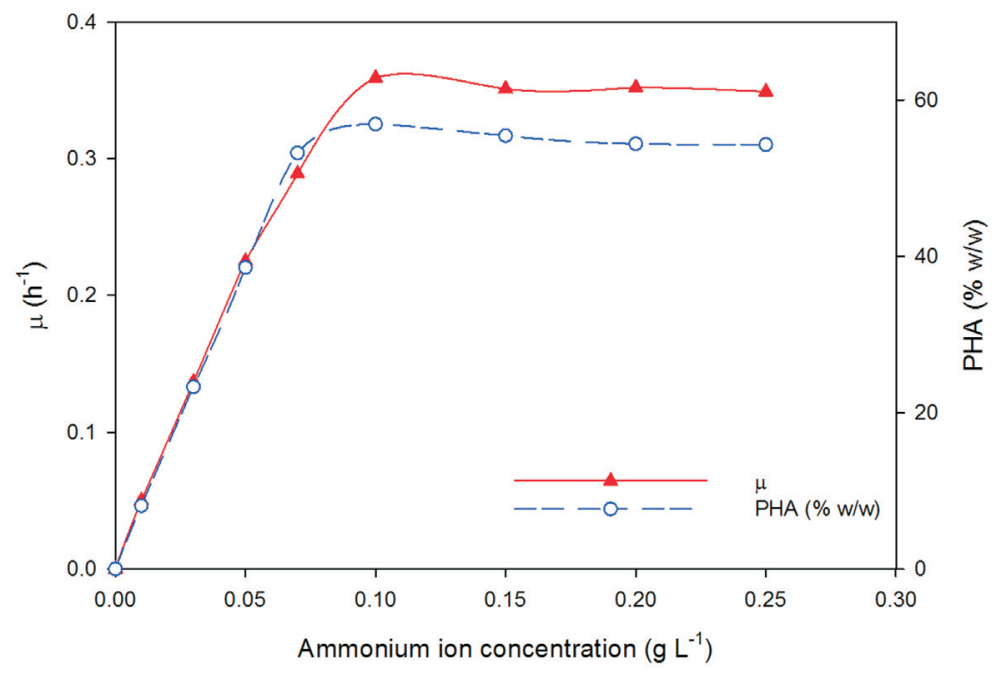

Figure 6 - Specific growth rate $(\mu)$ and PHA yield as a function of ammonium ion concentration in the biosynthesis of PHA by P. putida Bet001 using palmitic acid as sole carbon and energy source.

\section{Effect of carbon source on the polymer yield and volumetric productivity}

The effects of different types of fatty acids on PHA composition as well as the yield and volumetric productivity were studied. The composition of PHA accumulated by P. putida Bet001 grown on these carbon sources at $30^{\circ} \mathrm{C}$ for $48 \mathrm{~h}$ is presented in Table 2. PHA accumulation in the range of 49.7 to $68.9 \%(\mathrm{w} / \mathrm{w}) \mathrm{CDW}$ was observed. This observation is found to be in accordance with reported observation of increasing carbon source concentration under nitrogen limited condition increased the PHA accumulation in bacterial cells (Wang and Lee, 1997; Saranya and Shenbagarathai, 2010). The maximum volumetric productivity $(\Phi)$ of $1.44 \mathrm{~g} \mathrm{~L}^{-1} \mathrm{~h}^{-1}$ was observed when the organism was fed with $\mathrm{C}_{8: 0}$ to $\mathrm{C}_{18: 1}$ fatty acids resulting in a polymer of different monomeric units (C6 to $\mathrm{C} 14)$. However, it was observed that feeding oleic acid $\left(\mathrm{C}_{18: 1}\right)$ to this microorganism resulted in a higher PHA yield with a copolymer consisting of seven different monomers having both even ( $\mathrm{C} 4$ to C14) and odd monomeric (C7) units (Table 2). At first, 


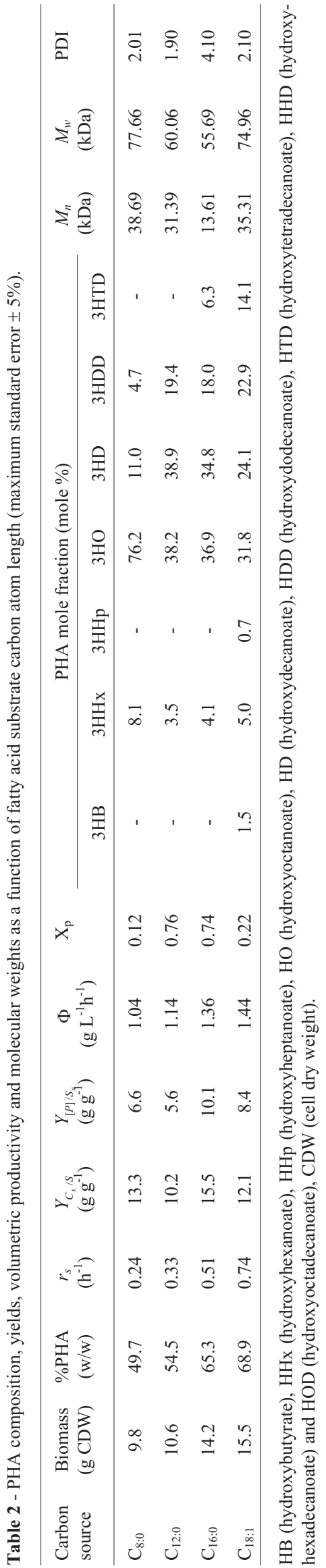

the presence of odd monomeric unit was considered as a possible contamination of the extracted polymer sample by cellular components. Thus, the purification step was repeated at least three times and the polymer re-extracted for GCMSMS analysis. The persistence of a strong signal from the mass spectrometry for the presence of the odd monomer unit (C7) entails re-consideration of the contamination hypothesis. From the conventional knowledge of $\beta$-oxidation of even-carbon-atom length fatty acids, it is not clear at this point the exact reason for the incorporation of an oddcarbon-atom length monomer like 3-hydroxyheptanoate (3HHp) into the polymer when oleic acid $\left(\mathrm{C}_{18: 1}\right)$ was used as a sole carbon and energy source for the bacterial growth and PHA accumulation. In our laboratory, further studies on the behaviour of medium-chain-length PHA biosynthesis in this particular bacterial strain is currently underway, which we hope will shed more light on this specific issue. The observed dominating mole contents of octanoate and decanoate monomers in $\mathrm{C}_{8: 0}$ to $\mathrm{C}_{18: 1}$ feeding regime is attributed to the fact that Peudomonas belonging to homology group I prefer to accumulate $\mathrm{C} 8$ and $\mathrm{C} 10$ monomer units in the PHA when fed with medium or long chain fatty acids (Haba et al., 2007).

The biomass yield on ammonium $Y_{C_{1} / S}$ were comparable for all types of fatty acids tested, while the polymer yields $Y_{[P] / S_{x}}$ on the other hand, were higher when $\mathrm{C}_{16: 0}$ and $\mathrm{C}_{18: 1}$ were used as sole carbon and energy source as compared to when $\mathrm{C}_{8: 0}$ and $\mathrm{C}_{12: 0}$ were fed to the microorganism (Table 2). The limiting substrate consumption rate $\left(r_{\mathrm{s}}\right)$ during balanced growth was found to increase as the carbon atom chain length of the substrate increases (Table 2). The reason for this observation is not clear at this stage. In terms of relative crystallinity $\left(X_{\mathrm{p}}\right)$ as compared to PHB, all the PHA produced from the different fatty acids in this study exhibited lower crystallinity (Table 2). Depending on the fatty acid used, the bacterium was observed to accumulate a polymer with average $M_{\mathrm{w}} \sim 77.7 \mathrm{kDa}$ when fed with caprylic acid $\left(\mathrm{C}_{8}\right)$. Feeding lauric acid $\left(\mathrm{C}_{12}\right)$ or palmitic acid $\left(\mathrm{C}_{16}\right)$ resulted in polymer accumulation with an average $M_{\mathrm{w}}$ of $60.1 \mathrm{kDa}$ or $55.7 \mathrm{kDa}$ respectively. When the carbon substrate was changed to oleic acid $\left(\mathrm{C}_{18: 1}\right)$, the organism was observed to accumulate unusual PHA make-up consisting of both even-chain and odd-chain carbon atom monomers with an average $M_{\mathrm{w}}$ of $\sim 74.9 \mathrm{kDa}$ (Table 2). The polymer produced by the bacterium showed average weight molecular weight $\left(M_{\mathrm{w}}\right)$ ranging from 55 to $78 \mathrm{kDa}$ while the number average molecular weight $\left(M_{\mathrm{n}}\right)$ showed a wider range between 13 to $39 \mathrm{kDa}$ (Table 2). The polydispersity index (PDI) of the PHA produced from different types of fatty acids range from 1.90 to 4.10 (Table 2).

\section{Conclusions}

In a batch fermentation, $P$. putida Bet001 was observed to accumulate PHA copolymer with accumulation yield spanning from 24 to $57 \%(\mathrm{w} / \mathrm{w}) \mathrm{CDW}$, depending on fermentation conditions. The batch kinetics of the process can be well described using models with substrate inhibi- 
tion parameter in particular Aiba and Webb models. The polymer analyses showed a variation in monomer contents that depends on the substrate carbon atom chain length fed. By changing the type of substrate in terms of carbon atom chain length in the fermentation process, the composition, yield and physico-mechanical properties of the accumulated polymer can be manipulated.

\section{Acknowledgments}

The Authors acknowledged University of Malaya for the research grants BK014-2014, RG165/11AFR, PV036/2012A and RP024-2012A.

\section{Conflict of Interests}

All the authors of the submission declare and clarify they do not have a direct financial relation with the commercial identities mentioned in the paper that might lead to a conflict of interest for any of the authors.

\section{References}

Agarry S, Audu T, Solomon B (2009) Substrate inhibition kinetics of phenol degradation by Pseudomonas fluorescence from steady state and wash-out data. Int J Environ Sci Technol 6:443-450.

Albuquerque MGE, Concas S, Bengtsson S, Reis MAM (2010) Mixed culture polyhydroxyalkanoates production from sugar molasses: The use of a 2-stage CSTR system for culture selection. Bioresour Technol 101:7112-7122.

Annuar MSM, Tan IKP, Ibrahim S, Ramachandran KB (2006) Ammonium Uptake and Growth Kinetics of Pseudomonas putida PGA 1. Asia Pac J Mol Biol Biotechnol 14:1-10.

Annuar MSM, Tan IKP, Ibrahim S, Ramachandran KB (2007) Production of medium-chain-length poly (3-hydroxyalkanoates) from crude fatty acids mixture by Pseudomonas putida. Food Bioprod Proc 85:104-119.

Annuar MSM, Tan IKP, Ibrahim S, Ramachandran KB (2008) A kinetic model for growth and biosynthesis of mediumchain-length poly-(3-hydroxyalkanoates) in Pseudomonas putida. Braz J Chem Eng 25:217-228.

Baei SM, Najafpour G, Younesi H, Tabandeh F, Issazadeh H, Khodabandeh M (2011) Growth kinetic parameters and biosynthesis of polyhydroxybutyrate in Cupriavidus necator DSMZ 545 on selected substrates. Chem Ind Chem Eng Q 17:1-8.

Burdon KL (1946) Fatty material in bacteria and fungi revealed by staining dried, fixed slide preparations. J Bacteriol 52:665.

Chung AL, Jin HL, Huang LJ, Ye HM, Chen JC, Wu Q, Chen GQ (2011) Biosynthesis and Characterization of Poly (3-hydroxydodecanoate) by b-Oxidation Inhibited Mutant of Pseudomonas entomophila L48. Biomacromolecules 12:3559-3566.

Dai Y, Lambert L, Yuan Z, Keller J (2008) Characterisation of polyhydroxyalkanoate copolymers with controllable four-monomer composition. J Biotechnol 134:137-145.

Francis L (2011) Biosynthesis of polyhydroxyalkanoates and their medical applications. Westminster, UK, 362p. (PhD. Thesis. School of life sciences, University of Westminster).
Grothe E, Chisti Y (2000) Poly (ß-hydroxybutyric acid) thermoplastic production by Alcaligenes latus: Behavior of fed-batch cultures. Bioproc Biosyst Eng 22:441-449.

Gumel AM, Annuar MSM, Heidelberg T (2012a) Biosynthesis and Characterization of Polyhydroxyalkanoates Copolymers Produced by Pseudomonas putida Bet001 Isolated from Palm Oil Mill Effluent. PLoS One 7:e45214.

Gumel AM, Annuar MSM, Heidelberg T (2012b) Effects of carbon substrates on biodegradable polymer composition and stability produced by Delftia tsuruhatensis Bet002 isolated from palm oil mill effluent. Polym Degrad Stab 97:12241231.

Gumel AM, Annuar MSM, Heidelberg T (2013) Current application of controlled degradation processes in polymer modification and functionalization. J Appl Polym Sci DOI: 10.1002/app.39006.

Gumel AM, Annuar SM, Heidelberg T (2013) Single-step lipasecatalyzed functionalization of medium-chain-length polyhydroxyalkanoates. J Chem Technol Biotechnol 88:13281335.

Haba E, Vidal-Mas J, Bassas M, Espuny MJ, Llorens J, Manresa A (2007) Poly 3-(hydroxyalkanoates) produced from oily substrates by Pseudomonas aeruginosa 47T2 (NCBIM 40044): Effect of nutrients and incubation temperature on polymer composition. Biochem Eng J 35:99-106.

Hofer P, Vermette P, Groleau D (2011) Production and characterization of polyhydroxyalkanoates by recombinant Methylobacterium extorquens: Combining desirable thermal properties with functionality. Biochem Eng J 54:26-33.

Huijberts G, Eggink G, de Waard P, Huisman GW, Witholt B (1992) Pseudomonas putida KT2442 cultivated on glucose accumulates poly (3-hydroxyalkanoates) consisting of saturated and unsaturated monomers. Appl Environ Microbiol 58:536-544.

Kansiz M, Domínguez-Vidal A, McNaughton D, Lendl B (2007) Fourier-transform infrared (FTIR) spectroscopy for monitoring and determining the degree of crystallisation of polyhydroxyalkanoates (PHAs). Anal Bioanal Chem 388:12071213.

Kim BS (2002) Production of medium chain length polyhydroxyalkanoates by fed-batch culture of Pseudomonas oleovorans. Biotechnol Lett 24:125-130.

Lee SY, Wong HH, Choi J, Lee SH, Lee SC, Han CS (2000) Production of medium-chain-length polyhydroxyalkanoates by high-cell-density cultivation of Pseudomonas putida under phosphorus limitation. Biotechnol Bioeng 68:466-470.

Li S, Dong C, Wang S, Ye H, Chen G-Q (2011) Microbial production of polyhydroxyalkanoate block copolymer by recombinant Pseudomonas putida. Appl Microbiol Biotechnol 90:659-669.

Liu Q, Luo G, Zhou XR, Chen G-Q (2011) Biosynthesis of poly(3-hydroxydecanoate) and 3-hydroxydodecanoate dominating polyhydroxyalkanoates by $\beta$-oxidation pathway inhibited Pseudomonas putida. Metab Eng 13:11-17.

Liu XW, Wang HH, Chen JY, Li XT, Chen GQ (2009) Biosynthesis of poly (3-hydroxybutyrate-co-3-hydroxyvalerate) by recombinant Escherichia coli harboring propionyl-CoA synthase gene (prpE) or propionate permease gene (prpP). Biochem Eng J 43:72-77.

Ma L, Zhang H, Liu Q, Chen J, Zhang J, Chen GQ (2009) Production of two monomer structures containing medium-chain- 
length polyhydroxyalkanoates by b-oxidation-impaired mutant of Pseudomonas putida KT2442. Bioresour Technol 100:4891-4894.

Mark JE (1999) Polymer data handbook.Oxford University Press, New York.

Marseno DW, Indrati R, Ohta Y (1998) A Simplified Method for Determination of Free Fatty Acids for Soluble and Immobilized Lipase Assay. Indo Food Nutr Prog 5:79-83.

Matsusaki H, Abe H, Taguchi K, Fukui T, Doi Y (2000) Biosynthesis of poly (3-hydroxybutyrate-co-3-hydroxyalkanoates) by recombinant bacteria expressing the PHA synthase gene phaC1 from Pseudomonas sp. 61-3. Appl Microbiol Biotechnol 53:401-409.

Ng K-S, Wong Y-M, Tsuge T, Sudesh K (2011) Biosynthesis and characterization of poly(3-hydroxybutyrate-co-3-hydroxyvalerate) and poly(3-hydroxybutyrate-co-3-hydroxyhexanoate) copolymers using jatropha oil as the main carbon source. Process Biochem 46:1572-1578.

Rai R, Yunos DM, Boccaccini AR, Knowles JC, Barker IA, Howdle SM, Tredwell GD, Keshavarz T, Roy I (2011) Poly-3-hydroxyoctanoate $\mathrm{P}$ (3HO), a medium chain length polyhydroxyalkanoate homopolymer from Pseudomonas mendocina. Biomacromolecules 12:2126-2136.

Randriamahefa S, Renard E, Guérin P, Langlois V (2003) Fourier transform infrared spectroscopy for screening and quantifying production of PHAs by Pseudomonas grown on sodium octanoate. Biomacromolecules 4:1092-1097.

Saranya V, Shenbagarathai R (2010) Effect of Nitrogen and Calcium Sources on Growth and Production of PHA of Pseudomonas sp. LDC-5 and its Mutant. Curr. Res J Biol Sci 2:164-167.

Satoh Y, Tajima K, Tannai H, Munekata M (2003) Enzymecatalyzed poly (3-hydroxybutyrate) synthesis from acetate with $\mathrm{CoA}$ recycling and NADPH regeneration in vitro. $\mathrm{J}$ Biosci Bioeng 95:335-341.

Sin MC, Annuar MSM, Tan IKP, Gan SN (2010) Thermodegradation of medium-chain-length poly (3-hydrox- yalkanoates) produced by Pseudomonas putida from oleic acid. Polym Degrad Stab 95:2334-2342.

Siracusa V, Rocculi P, Romani S, Rosa MD (2008) Biodegradable polymers for food packaging: A review. Trends Food Sci Technol 19:634-643.

Solorzano L (1969) Determination of ammonia in natural waters by the phenolhypochlorite method. Limnol Oceanogr 14:799-801.

Spiekermann P, Rehm BHA, Kalscheuer R, Baumeister D, Steinbüchel A (1999) A sensitive, viable-colony staining method using Nile red for direct screening of bacteria that accumulate polyhydroxyalkanoic acids and other lipid storage compounds. Arch Microbiol 171:73-80.

Thomson N, Roy I, Summers D, Sivaniah E (2010) In vitro production of polyhydroxyalkanoates: Achievements and applications. J Chem Technol Biotechnol 85:760-767.

Venkateswar Reddy M, Venkata Mohan S (2012) Effect of substrate load and nutrients concentration on the polyhydroxyalkanoates (PHA) production using mixed consortia through wastewater treatment. Bioresour Technol 114:573-582.

Vishnuvardhan RS, Thirumala M, Mahmood S (2009) Production of PHB and P (3HB-co-3HV) biopolymers by Bacillus megaterium strain OU303A isolated from municipal sewage sludge. World J Microbiol Biotechnol 25:391-397.

Wang F, Lee SY (1997) Poly (3-Hydroxybutyrate) Production with High Productivity and High Polymer Content by a Fed-Batch Culture of Alcaligenes latus under Nitrogen Limitation. Appl Environ Microbiol 63:3703-3706.

Xu J, Guo BH, Yang R, Wu Q, Chen GQ, Zhang ZM (2002) In situ FTIR study on melting and crystallization of polyhydroxyalkanoates. Polymer 43:6893-6899.

Xue L, Dai S, Li Z (2010) Biodegradable shape-memory block co-polymers for fast self-expandable stents. Biomaterials 31:8132-8140.

All the content of the journal, except where otherwise noted, is licensed under a Creative Commons License CC BY-NC. 